\title{
Misinterpretations of Intercultural Communication among Chinese Foreign Language Educators
}

\author{
Qunxing Zhang \\ Beijing Information Science \& Technology University, China
}

\begin{abstract}
When a large number of foreign language teachers are actively involved in intercultural communication study, more and more scholars have shown great concern about the "aphasia" of the Chinese native culture in foreign language teaching and learning. The paper makes an analysis on some existing misinterpretations of intercultural communication, and argues that, to a certain extent, the misinterpretations are a big factor for the "Aphasia" of the Chinese culture in foreign language education. Some suggestions are thus put forward to approach such a problem.
\end{abstract}

Index Terms-intercultural communication, misinterpretations, "aphasia" of the Chinese culture, foreign language education

\section{INTRODUCTION}

What is intercultural communication (IC)? A great many scholars, including Hall (1959), the father of IC study, Gudykunst \& Kim (2007), Lustig \& Koester (2007), Chen \& Starosta (2007), Samovar \& Porter (2007), Varner \& Beamer (2006), Scollon \& Scollon (2000), Singer (1987), to name just a few, have posed their definitions in the last 50 years since the IC study was born in the U.S. For instance, Gudykunst \& Kim defined IC as "a transactional, symbolic process involving the attribution of meaning between people from different cultures" (2007, p.17). Lustig \& Koester maintained that "Intercultural communication occurs when large and important cultural differences create dissimilar interpretations and expectations about how to communicate competently" (2007, p.52). Samovar \& Porter proposed that "intercultural communication entails the investigation of those elements of culture that most influence interaction when members of two or more cultures come together in an interpersonal setting" (2007, p.8). Chen \& Starosta held that "successful intercultural communication is based on the positive feeling and beliefs we bring to the intercultural encounter and on the behavioral skills we possess" (2007, p.30). And Marshall Singer (1987) even claimed that communication between every two persons is intercultural communication.

There is a variety of ways in which the topic of IC can be explored. Some examine IC from a macro point of view with focus on communication between different nations, ethnics and races while some are mainly concerned with the more personal aspects of people from different cultures interact face-to-face. Just as Lustig \& Koester said, "we chose our specific definition because of its usefulness in explaining the thoughts and ideas we wish to convey" (2007, p.9). The term IC has been used in many ways for varied, and not always consistent, purposes.

IC, as an interdisciplinary field of study closely connected with many traditional subjects, contains a wide variety of content, not only including the general research projects, such as the relationship of language, culture and communication, components of culture, layers of cultural analysis and the process of intercultural communication, but also including the pragmatic studies on various cultures, the contrastive study of different cultures, nonverbal communication, intercultural adjustment, the development of intercultural competence and so on (Zhang, 2007, p.22).

All the definitions of IC seem to be broad, abstract and even all-inclusive. And so do the concepts of intercultural communicative Awareness (ICA) and intercultural communicative competence (ICC). For instance, Ruben (1976) identified seven dimensions of ICC: the capacity to be flexible, the capacity to be nonjudgmental, tolerance for ambiguity, the capacity to communicate respect, the capacity to personalize one's knowledge and perceptions, the capacity to display empathy, and the capacity for turn taking. Hammer, Gudykunst, and Wiseman (1978) and Hammer (1987) specified the three major factors of ICC: ability to deal with psychological stress, ability to communicative effectively and the ability to establish interpersonal relationships. Wiseman (2002) stated "ICC involves the knowledge, motivation, skills to interact effectively and appropriately with members of different cultures" (2002, p.208). However, knowledge of such explanations and guidelines does not assure the success of the FL teacher in helping students develop ICA and ICC in the context of FL education in china.

\section{IC STUdy In CHINA's FL EdUCATION FIELD}

Ever since IC study was introduced into China in the 1980s, it has been tightly bound to FL education and has won great concern of FL scholars and teachers, who were the first to get engaged in IC study in China and now are still the 
main research force of this field. It was in 1997 that Prof. Jia Yuxin stated that "IC had become a hot research project in the Chinese FL education field" (1997, p.1). Today it can be safely said that IC is not only a hot project, but also a must-explore topic for the FL teachers, because the College English Syllabus and the Syllabus for English Teaching of English Majors in Higher Education lately issued by the State Education Commission of China (SECC) have both explicitly set a demand to foster talents with intercultural communicative awareness and competence.

The recent years have witnessed rapid development of IC study in the Chinese FL education field. We see evidence of this everywhere, in the titles of papers and articles and dissertations. According to the statistics made by the author on the topics of "intercultural communication" and "foreign language teaching" (FLT) in the Chinese Journal Full-text Database (CJFD), altogether 3,276 articles are found during the recent 10 years from 2004 to 2013 (See Table 1), and up to 1880 articles during 2009 to 2013.

TABLE 1

ARTICLES ON THE TOPICS OF IC AND FLT FROM 2004 - 2013

\begin{tabular}{|l|l|l|l|l|l|l|l|l|l|l|}
\hline Year & 2004 & 2005 & 2006 & 2007 & 2008 & 2009 & 2010 & 2011 & 2012 & 2013 \\
\hline Articles & 209 & 216 & 260 & 327 & 384 & 443 & 388 & 404 & 364 & 281 \\
\hline
\end{tabular}

The articles have discussed about the relationship between IC and FL instruction from different angles, such as the cultivation of ICA and ICC, the content of IC in FL teaching, cultural introduction in classes, the analysis of cultural meaning of words, nonverbal communication, pragmatic misuse, pragmatic capability and rules, intercultural teaching methods and etc. Although educators have been putting forward various arguments from different standpoints, it is for sure that the Chinese FL education field has already reached the consensus that the ultimate objective of FL instruction is to develop the students' ICA and equip them with the competence to communicate with people from different cultural backgrounds.

Given the limited time available for FL education in China and the lack of authentic foreign language and culture environment, there is no question that we should examine or re-examine what IC, ICC and ICA mean and give more consideration on how to develop these definitions appropriately in the context of the Chinese FL education.

It should be noted that the Chinese FL teachers do not necessarily share a common understanding of IC, ICA or ICC. Then how do the Chinese FL teachers interpret these terms? With these questions in mind, we analyzed a number of articles and found that difference does occur in the teachers' interpretations of IC in the context of FL teaching and learning and that many teachers tend to explain IC with the target language and culture as the focus.

\section{APHASIA OF THE CHINESE CULTURE IN FL EDUCATION}

Early in 1996, Cao Shunqing (1996) sharply pointed out that the contemporary Chinese theories of literature and art had been suffering from aphasia for a long time. When FL educators are actively involved in heated discussions on IC, however, more and more voices have been heard about the "aphasia" of the Chinese culture in recent years. Some educators (Yuan Fang, 2006; Zhang Lan, 2003; Zhang Youping, 2003) even argue that serious symptoms of "aphasia" have been shown in the current Chinese FL education field. Discussions have been made recently on the "aphasia" of the Chinese culture in terms of FL teaching materials, teachers, teaching approaches and learners. But less than 50 articles among the 2,199 mentioned above put focus on this phenomenon, taking up a proportion of about $2.3 \%$. Various reasons work together and finally lead to the aphasia of the Chinese native culture in FL class, among which some misinterpretations of IC are indeed a big contributory factor.

\section{Misinterpretations OF IC IN THE FL EDUCATION IN CHINA}

\section{A. Misinterpretation 1: IC Is the Communication in the Target Language}

Here are some interpretations of IC in the context of FL teaching and learning made by certain teachers. The ultimate objective of FL education is to equip the students with the ability to communicate with the outside world in the target language to absorb knowledge and obtain information (Yan \& Liu, 2008). The ultimate purpose of college English teaching is to educate the students to undertake effective IC activities in standard English (Zhou, 2007). Although IC is frequently mentioned by teachers, it seems that they tend to put their focus on "the introduction of the target culture, seldom touching upon the native one" (Liu, 2003). In fact, it is a commonplace in the FL education world of China for a long period of time to lay emphasis on the target language and culture with a neglect of the native language and culture.

A number of FL teachers do not have a good mastery of the Chinese language or the native cultural knowledge. This shortage, undoubtedly, constitutes a big hindrance to the development of teachers themselves and the quality of FLT. According to the investigation made by Deng \& Ao (2005) among the English teachers for English majors of 10 colleges and universities in Sichuan Province, all the teachers, to different extents, lack the knowledge both in terms of the native culture and in terms of the English expressions of the Chinese culture. They also point out that the number of the teachers who never mention the native culture in classes constitute $50 \%$ of the total. Furthermore, teachers are unlikely to acquire a really authentic and standard foreign language and culture, because they are learners themselves and may also face the problem of langue "fossilization" (Ellis, 1994, p.353). Therefore, it is no way to create an authentic context for students or to educate them to communicate with foreigners effectively in standard English. 
Teachers, as the decision-maker of all class activities, their own awareness and conception may make a great impact on the whole teaching process ranging from the choice of teaching materials, the arrangement of teaching tasks, the adoption of teaching modes and methods and so forth. Their misinterpretations of IC are sure to affect the education of foreign language talents.

It is also a common phenomenon that students overlook the study of the Chinese language and culture. They seem to attach more importance to the input and absorption of the foreign culture. According to the questionnaire survey made by the author on 115 non-English majors, nearly $90 \%$ of the students have realized the necessity and importance of learning English culture, but only 4 agree to regard the diffusion of the Chinese culture in English to the outside world as one of the main objectives of English learning as well as an important criterion to measure the effectiveness of learning English. The result shows that most of the students have realized the importance of learning culture, especially the western culture, but they have not formed an appropriate attitude towards the native culture.

Does the FL education with the purpose of IC just refer to the teaching and learning of the target language and culture? I am afraid the answer is negative. IC is a bilateral communicative process. At times the failure of IC activities is not due to the lack of the foreign culture knowledge, but due to the shortage of the native culture knowledge. A great many researchers have put too much emphasis on ethnocentrism, bias towards foreign culture and cultural stereotypes which may lead to the "negative transfer" of the native culture in FL learning (Hu, 2005; Liang \& Xu, 2007). However, it should be warned against the neglect of the Chinese culture in FL education in the meantime.

\section{B. Misinterpretation 2: ICA Is the Awareness of the Target Culture}

\section{Misinterpretation 3: ICC Is the Competence of the Target-culture Empathy}

ICA and ICC are closely related to each other, which are often mentioned together by researchers. Awareness is the first stage toward the development of ICC, because only after awareness has been aroused can FL learners endeavor to develop intercultural communicative skills, accumulate knowledge and enhance understanding on their own initiative. But comparatively speaking, ICA is explored much less and sometimes it is equated with ICC. Here is a definition of ICA, which states "FL learners have a good mastery of the target culture knowledge ... and can think, react and undertake various communicative activities as native speakers do" (Tan, 2009). There is a pressing need for FL teachers to make more discussions on ICA and cultivate an appropriate ICA themselves to help their work. The teacher must learn to be aware of his or her own cultural values before helping students become culturally aware (Irving, 1984).

As for ICC, many educators seem to equate it with Communicative Competence (CC). Among the 635 papers found in CJFD with ICC as the title in recent 10 years, about 140 are based on the theories of CC proposed by Hymes, Canale and Swain. According to Hymes, CC "is integral with attitudes, values, and motivations concerning language, its features and uses" (1972, p.270). In his notion, language behavior is viewed in terms of its grammaticality (formal correctness), appropriateness and effectiveness (sociolinguistic correctness). In short, it is the competence as to when to speak, when not, and as to what to talk about with whom, when, where, in what manner. Canal \& Swain (1980) advanced a broader notion of CC, which includes grammatical competence (knowledge of lexical items and of rules of morphology, syntax, sentence-grammar semantics, and phonology), sociolinguistic competence (made up of two sets of rules, sociocultural rules of use and rules of discourse), and strategic competence (composed of verbal and nonverbal communication strategies relating to grammatical competence and sociolinguistic competence). But some linguists, such as Byram (1997) and Kramsch (1998), have begun to doubt their CC theories which regard the linguistic and sociocultural behaviors of native speakers as the target and model, and they are opposed to judging the competence of FL learners according to the grammatical and sociocultural criteria of native speakers. However, with respect to ICA and ICC, educators tend to define them with the target language and culture as the model. For instance, "students should be cultivated to be able to use authentic and standard English... and to express their ideas appropriately according to the cultural customs of English-speaking countries" (Wu, 2006); "the success of communication is guaranteed by the grammatical and cultural appropriateness of English expression” (Xiong, 2006).

Zhang Hongling (2007, p.77-78) points out it is absurd to make the cultivation of "native speakers" as the goal of FL education mainly for three reasons. First, a variety of English languages existing in the world, such as British English, American English, Australian English and etc., make it impossible to define what a native speaker is like. In other words, the concept of "native speakers" is so abstract and vague that it is hard to integrate it into teaching. Second, the requirement that students should achieve the same linguistic and cultural competence as native speakers just ignores the fact that FL learners are learning or acquiring the foreign language in a context quite different from that for native speakers. In fact, no matter how much effort they make, it is by no means likely for FL learners to improve their target language to a fairly proficient and standard level (Zhao, 2001). Besides, we are all bound by our own cultural schemata and thus, interpreting cultural phenomena is always subject to our own subjective interpretation (Schulz, 2005). However, part of the universal human experience is the tendency to take our own culture for granted. We live it, we act it, we think it, we do it - but usually we are not consciously aware of the influence of our cultural values on our behavior and attitudes (Irving, 1984). Third, even if the learners can achieve the competence of a native speaker, it is totally unnecessary because it means they have to break away from their own culture to get assimilated into the target one. Zhang \& Tian (2004), after their field study and personal experience in New York for more than one year, deeply realized that when teaching students knowledge about the target language and culture, FL educators should also develop 
the awareness of the native language and culture and equip them with the capability to correctly and effectively express the native culture in the target language.

Besides, the term "cultural empathy" is often mentioned when ICC is explained. For example, cultural empathy in IC is to communicate on the stance of the target culture (Zhang, 2001); cultural empathy is to consciously transform your cultural stance, to transcend the habit and framework of your native culture, free yourself from its constraints, and put yourself in the midst of the target culture to sense and understand it (Zhao, 2006; Chen \& Yuan, 2008). The prerequisite for these interpretations is that learners can directly experience the target culture to accumulate knowledge of that culture, appropriate cultural behaviors, fluency in the language, and ultimately change their cultural attitudes. However, in FL classrooms, learners do not generally have access to direct experiences or interactions in the culture (Moran, 2003, p.120), and they cannot stop their contact with the Chinese culture to learn English. Empathy, an important emotional factor for communication in linguistic research, does not mean giving up your own feeling to blindly agree with others. Cultural empathy is, and should be always based on the native culture of FL learners.

\section{Suggestions}

With the speeding up of the global communication and integration, IC is getting more and more essential for higher education. What sort of definition of IC should be adopted for the context of FLT in China? What sort of ICA and ICC should be integrated with FLT? The profession needs to develop some consensus as to these issues, and identify some concise, foundational and, of course, realistic objectives as well as principled approaches for the IC instruction in FLT. In view of this necessity, what I am advocating here is to define these terms as follows:

IC is communication between the target culture and the native culture on a reciprocal basis.

ICA is the awareness of the target culture and the native culture by means of objective, non-judgmental comparisons.

ICC is the competence to communicate with people from the target culture on an equal basis.

The purpose of FL learning is not to be assimilated by the target language and culture, but to achieve bilateral communication on an equal basis. Thus efforts are supposed to be made in the following aspects:

(1) Given the characteristics of China's FL teaching context, it is an efficient means to make full use of language classes to undertake intercultural communicative instruction and engage students actively in the process of analyzing cultural similarities and differences based on available teaching materials. Therefore, there is a need to set up an intercultural teaching mode aimed at developing an intercultural awareness with equal priority to target culture and native Culture. Actually the clues to culture and cross-cultural (intercultural) awareness are everywhere - all we need do is learn to recognize them, and then to integrate them into activities in the classroom to increase cross-cultural (intercultural) understanding (Irving, 1984).

(2) The Chinese culture knowledge should be incorporated into FL teaching materials to develop the students' awareness and competence to diffuse the native culture to other countries while they are learning and absorbing the target language and culture.

(3) If, indeed, ICA and ICC are to be an outcome of FL education, we need to include such awareness and competence in its curricular goals. Furthermore, these objectives must be formally and routinely assessed as are the linguistic objectives in FL programs.

(4) Comparative and contrastive teaching method should be strengthened. Comparison and contrast, participation and experience are the most frequently applied methods for intercultural FL education (Zhang, 2007, p.240). When we communicate with people from other cultures, we often are confronted with languages, rules, and norms different from our own. Confronting these differences can be a source of insight into the rules and norms of our own culture (Gudykunst \& Kim, 2007, p.4). It is precisely those comparative and contrastive approaches to the study of culture that promise to bring the most rewards since they broaden the student's knowledge and understanding of the home culture as well as the foreign culture (Schulz, 2005).

(5) To make students stimulate and improve their ICA and ICC, teachers should bring students' initiative and potential into full play by organizing a variety of activities or designing a lot of meaningful and inspiring tasks in and out of classes.

(6) The quality of FL educators, to a great extent, determines the quality of FL education. How are teachers prepared to teach and assess intercultural learning in the FL classroom? Is teacher development adequate for the systematic exploration of the native and target cultures and for developing ICA and ICC in their students? It is of vital importance to train teachers and encourage them to get actively involved in IC activities and enrich their own intercultural experience. It can be argued that teacher development is the key to strengthening and enhancing IC instruction in FL teaching field.

\section{CONCLUSION}

IC, ICA and ICC, which are all abstract but must-explore concepts, can mean different things for different groups of educators and researchers. Not until some consensus is reached regarding appropriate objectives, contents, approaches, and assessments on the basis of the Chinese FL education context can it help to fulfill of the ultimate goal of FLT of cultivating students' ICA and ICC. Moreover, we must make a conscious effort to increase awareness of our native 
culture in order to better understand another culture in intercultural communication. If misinterpretations are formed concerning these terms, they are sure to affect the FLT which is now indispensable to IC.

\section{REFERENCES}

[1] Byram, M. (1997). Teaching and Assessing Intercultural Communicative Competence. Clevedon, UK: Multilingual Matters.

[2] Canale, M. \& M. Swain. (1980). Theoretical Bases of Communicative Approaches to Second Language Teaching and Testing. Applied Linguistics, 1, 1-47.

[3] Cao, Shunqing. (1996). Cultural Aphasia and Cultural Morbidity. Literature and Art Forum, 2, 50-58.

[4] Chen, er'chun \& Yuan, Zhiming. (2008). A Study on Cultural Empathy Competence and Intercultural Awareness. Journal of Sichuan International Studies University, 24(3), 138-140.

[5] Chen, Guo-Ming \& W. J. Starosta. (2007). Foundations of Intercultural Communication. Shanghai: Shanghai Foreign Langue Education Press.

[6] Deng, Wenying \& Ao, Fan. (2005). Analysis of English Major Students' Chinese Culture Aphasia. Journal of Bingtuan Education Institute, 15(4), 58-61.

[7] Ellis, R. (1994). The Study of Second Language Acquisition. Oxford: Oxford University Press.

[8] Gudykunst, William B. \& Y. Y. Kim (2007). Communicating With Strangers: An Approach to Intercultural Communication (Fourth Edition). Shanghai: Shanghai Foreign Langue Education Press.

[9] Hall, E. T. (1959). The Silent Language. Garden City, NY: Doubleday.

[10] Hammer, M. R., W. B. Gudykunst \& R. C. Wiseman. (1978). Dimensions of intercultural effectiveness: An explanatory study. International Journal of Intercultural Relations, 2, 382-392.

[11] Hammer, M. R. (1987). Behavioral dimensions of intercultural effectiveness: A replication and extension. International Journal of Intercultural Relations, 11, 65-88.

[12] Hu, Chao. (2005). Intercultural Awareness and Intercultural Communication Competence: A Survey of a Chinese Campus. Foreign Languages in China, 2 (3), 60-64.

[13] Hymes, D. (1972). On Communication Competence. In J. B. Pride \& J. Holmes (eds). Sociolinguistic: Selected Readings. Harmondsworth, England: Penguin Books, 269-293.

[14] Irving, Kathy J. (1984). Cross-Cultural Awareness and the English-as-a-Second-Language Classroom. Theory into Practice, 23 (2), 138-143.

[15] Jia, Yuxin. (1997). Intercultural Communication. Shanghai: Shanghai Foreign Language Education Press.

[16] Kramsch, C. (1998). The privilege of the intercultural speaker. In M. Byram and M. Fleming (eds), Language Learning in Intercultural Perspective: Approaches Through Drama and Ethnography. UK: Cambridge University Press, 16-31.

[17] Liang, Lanfang \& Xu, Guiyan. (2007). Cultural Acquisition in Foreign Language Study. Education Exploration, 6, 50-51.

[18] Liu, Changjiang. (2003). Integration of Foreign Culture and Native Culture into FLT. Foreign Language World, 4, 14-18.

[19] Lustig, Myron W. \& J. Koester. (2007). Intercultural Competence: Interpersonal Communication Across Cultures (Fifth Edition). Shanghai: Shanghai Foreign Langue Education Press.

[20] Moran, Patrick R. (2003). Teaching Culture: Perspectives in Practice. Beijing: Foreign Language Teaching and Research Press.

[21] Ruben, B. D. (1976). Assessing communication competency for intercultural adaptation. Group and Organizational Studies, 1, 334-354.

[22] Samovar, Larry A. \& R. E. Porter. (2007). Intercultural Communication: A Reader (Tenth Edition). Shanghai: Shanghai Foreign Langue Education Press.

[23] Schulz, R.A., J. F. Lalande II, P. Dykstra-Pruim, H. Zimmer-Loew, \& C. J. James. (2005). In Pursuit of Cultural Competence in the German Language Classroom: Recommendations of the AATG Task Force on the Teaching of Culture. Teaching German, $38(2), 172-181$.

[24] Scollon, Ron \& S. W. Scollon. (2000). Intercultural Communication: A Discourse Approach. Beijing: Foreign Language Teaching and Research Press \& Blackwell Published Ltd.

[25] Singer, M. (1987). Intercultural Communication: A perceptual approach. Englewood Cliffs, NJ: Prentice Hall.

[26] Tan, Ling. (2009). Intercultural Communication Awareness and College English Teaching. China Adult Education, 1, $157-158$.

[27] Varner, Iris \& L. Beamer. (2006). Intercultural Communication in the Global Workplace. Shanghai: Shanghai Foreign Langue Education Press.

[28] Wiseman, R. L. (2002). Intercultural Communication Competence. In William B. Gudykunst \& Bella Mody (Eds.), Handbook of International and Intercultural Communication (2nd Edition), London: Sage Publications Ltd., 207-224.

[29] Wu, Yingli. (2006). On Cultivation of Learners' Cross-Cultural Communicative Competence in ELT. Journal of Yancheng Teachers College(Humanities \& Social Sciences Edition), 26 (6), 77-79.

[30] Xiong, Shufen. (2006). Intercultural Communication and FLT. Cross-cultural Communication, 2 (4), 100-103.

[31] Yan, Li \& Liu, Shilin (2008). Culture and Language Teaching. Journal of Yichun College, S1, 76-77.

[32] Zhang, Hongling. (2007). Intercultural Approach to Foreign Language Teaching. Shanghai: Shanghai Foreign Language Education Press.

[33] Zhang, Lan. (2003). Analysis of Aphasia of the Chinese Native Culture in Intercultural Communication. Journal of Southwest University (Humanities \& Social Sciences), 24(8), 339-341.

[34] Zhang, Youping. (2003). Rethinking on Language Teaching and Culture Teaching. Foreign Language World, 95(3), 41-48.

[35] Zhang, Xirong \& Tian, Dexin (2004). Two-way Interaction in Intercultural Communication. Journal of Xi'an International Studies University, 12(2), 17-19.

[36] Zhang Haiyan. (2001). Cultural Empathy and FLT. Journal of Suzhou Education Institute, 1, 81-82.

[37] Zhao, Guihua. (2006). Barriers to Cultural Empathy in Intercultural Communication and Solutions. Academic Exchange, $144(3), 167-169$.

[38] Zhao, Zhongde. (2001). Problems in English Teaching in China. Foreign Languages and Their Teaching, 150(10), 38-42. 
[39] Zhou, Zhenfang. (2007). How to Develop Non-English Major Students' Intercultural Communicative Awareness. Journal of Huaihua University, 26(6), 92-93.

Qunxing Zhang was born in Tianmen, China in 1979. She received his M.A. degree in English Language and Literature from Guizhou University, China in 2003.

She is currently an associate professor in the School of Foreign Languages, Beijing Information Science \& Technology University, Beijing, China. Her research interests include translation studies and intercultural communication. 